\title{
Volunteering as Media Work: The Case of the Eurovision Song Contest
}

\author{
By Fredrik Stiernstedt \& Irina Golovko
}

\begin{abstract}
This article explores volunteering in relation to the Eurovision Song Contest (ESC), which took place in Stockholm in 2016 and in Kyiv in 2017, with the aim of shedding light on volunteering as a form of "media work". Following from this, the article aims to problematize the theoretical concept of free labour and analyse the symbolic exchanges and currencies involved in employing a "free" labour force. Through interviews with volunteers, this article explores what volunteers at huge media events do, how their work is organized, and what motivates them. The empirical basis for this article is an interview study with volunteers and volunteer organizers of the ESC in Stockholm (May 2016) and in Kyiv (May 2017), complemented with a document analysis of volunteer guidebooks and organizational reports. The article shows that eventfulness is an essential part of what volunteer labour brings to an event such as the ESC. It is also a key element in the production of economic value: eventfulness is a currency that expresses the value of the event itself and is a key feature of place branding. Furthermore, eventfulness along with the feeling of being a part of an event, of something bigger, as it unfolds in time - is a key feature of the motivation for the volunteers who contribute with unpaid labour. As such, eventfulness can also be understood as a form of currency or symbolic capital that forms the main remuneration or "wage" earned by volunteers at an event such as the ESC.
\end{abstract}

Keywords: media work; volunteering; free labour; Eurovision Song Contest

Stiernstedt, Fredrik \& Irina Golovko: "Volunteering as Media Work: The Case of the Eurovision Song Contest", Culture Unbound, Volume 11, issue 2, 2019: 231-251. Published by Linköping University Electronic Press: $\underline{h t t p: / / w w w . c u l t u r e u n b o u n d . ~}$ ep.liu.se 


\section{Introduction}

Media and cultural events such as the Eurovision Song Contest (ESC) rely on volunteer work to a high degree. In this, they are like other mega-events, such as the World Cup in football or the Olympics. This article explores volunteering during the ESC in Stockholm 2016 and in Kyiv 2017, and sheds light on volunteering as a form of "media work" (Deuze 2007). Volunteering can be a form of unpaid labour, when performed with or in relation to commercial interests; with this concept as a basis, the purpose of this article is to problematize the concept of free labour and highlight the symbolic exchanges and currencies involved in this form of media work. The article hence asks: what symbolic currencies are involved in free labour at the ESC, how are such symbolic renumerations produced and transferred, and what role do they play for the people involved in free labour? Through interviews with volunteers, this article explores what volunteers at large media events do, how their work is organized, how the volunteers themselves understand their role, what motivates them, and how the organizers of the event work to maintain motivation among volunteers.

Free and unpaid labour is nothing new in the media industries; in fact, it is an intrinsic part of how the media industries are organized, in both traditional media (television, print, film) and new media industries (social network media, wikis) (Lindgren 2014, Osman 2014). Research and theoretical debate on this kind of free labour in the media industries has been lively during the last decade (Banks \& Deuze 2009, Banks \& Humphreys 2008, Fuchs 2014, Gill \& Pratt 2008, Hesmondhalgh 2010). However, the kind of unpaid labour that is conducted during large media events in the form of volunteering has not been given much attention in previous research. Although volunteers are arguably working without salary, their efforts are rewarded with other forms of compensation. For example, in previous research, unpaid media labour has been theorized as "hope" or "aspirational" labour (Duffy 2017, Kuehn \& Corrigan 2013), in which the motivation for participating is the hope or implied promise of a future career. Volunteering has also been understood as being motivated by altruism and an aspiration to "do good" (Smith 1981). For the volunteers interviewed for this article, neither career motives nor an aspiration to "do good" were sufficient motivators for performing unpaid labour. Rather, another symbolic currency compensated for and motivated their efforts: participation in and experience of the event, and the sense of belonging that such participation provides. This symbolic currency places demands on the organizers of events such as the ESC, who must provide and organize eventfulness not only as an external experience to the audiences, but also as an internal experience within the organization of volunteers.

This article draws on interviews with volunteers and volunteer organizers of the ESC in Stockholm (May 2016) and in Kyiv (May 2017), complemented with a 
document analysis of volunteer guidebooks and organizational reports.

Aside from its general theoretical basis regarding volunteering at media events as a form of free labour in the media industries, this article highlights some of the specificities of volunteering in two countries - Sweden and Ukraine. Much of the previous research on volunteering has been conducted within the United Kingdom and the United States, with the specificities that come with those national settings. Ukraine is an especially interesting case, since volunteering in this country has taken on a specific form due to the events of Euromaidan and the Crimean crisis. During the Maidan revolution in 2013, a range of volunteer organizations formed to support and aid the protesters; these organizations have lived on through the current military conflicts in Eastern Ukraine, and have taken on a range of tasks that are usually handled by the state (e.g., healthcare and supplying soldiers with equipment and food). The weak state in Ukraine, together with the rise of volunteerism and the mushrooming of NGOs, has created a "state within the state" (Dunnett 2015): a parallel structure of civil society organizations that uphold many central functions within the country. At first consideration, volunteering at a media event such as the ESC may seem to be completely different from volunteering in a military conflict. However, the way in which the volunteering is organized connects these seemingly different kinds of volunteering, and the participants in our study generally treated them as part of the same "volunteering movement". Sweden is also somewhat of an outlier in international comparisons on volunteering. A widespread idea exists that the volunteering sector in Sweden has been inhibited by the powerful expansion of the Social Democratic welfare state, which has rendered unnecessary or discouraged non-profit involvement and voluntary organization (e.g., Weisbrod 1997). In fact, Lundström and Svedberg (2003) have shown that this is a misunderstanding, at least to some extent. The voluntary sector in Sweden is as strong as that of any other comparable industrial country, whether measured in terms of economic importance, membership figures, or popular participation in voluntary activities (Lundström \& Svedberg 2003). Sweden differs from other countries, however, in that its volunteering sector has limited importance in the "core" areas of the welfare state, such as care of the elderly or of children. Another important difference is that voluntary work in Sweden is almost entirely organized through membership organizations (e.g., organizations for pensioners or labour unions). Against this background, volunteering may have different meanings and take on different forms and shapes in different countries. 


\section{What is volunteering?}

Rochester et al. (2016) distinguish between three distinct paradigms of volunteering. The first is the non-profit paradigm, which is considered in previous scholarly work and in public discourse to be dominant. The second paradigm is volunteering as a form of activism, such as in political or religious movements. The third paradigm, which is the most relevant for this article, is volunteering as a form of "serious leisure". This kind of volunteering is found in the areas of arts and culture, and sports and recreation. Rochester et al. (2016) mention a range of different activities, from one-off occasional volunteering, such as selling hot dogs at one's child's sports event, to more long-term and steady hobby-based activities, such as engagement in an amateur theatre company. A third kind of "serious leisure" identified by Rochester et al. (2016) is a project-based arrangement that is somewhat long-term and that may be organized within a large and complex organization. The ESC is a good example of this form of volunteering, although it differs to some extent from other examples of "serious leisure", which arguably show a stronger focus on small, local, and amateur-based cultural events.

Furthermore, volunteering has traditionally been associated with the so-called "third sector": civil society. To volunteer has been to engage in work outside of the circuits of capital and markets, in a way that is autonomous from both commercial and state interests. According to Salamon and Sokolowski (2016), this conceptualization of a "third sector" might be both too narrow and problematic, however, and the case of the ESC underlines their point. State, commercial, and third-sector interests are highly intertwined in mega-events such as the ESC. NGOs may in effect both be and operate as commercial enterprises, or may be directly and formally tied to the state - a point that will be elaborated further in the empirical section on how volunteering for the ESC is organized.

\section{Free labour and ESC volunteers}

The volunteers for the ESC demonstrated a range of altruistic and idealistic intentions and reasons for their engagement in the event. Nevertheless, volunteering in a large-scale cultural and media event contributes to the accumulation of economic capital and can hence be seen as labour, according to the Marxist definition of the term (Fuchs 2014). That is, the work performed by volunteers is a precondition for the event as such to be able to take place and, accordingly, is also a precondition for local and multinational businesses of various sorts to be able to generate profits. Of course, the ESC is a televised music event managed through cooperation within the European Broadcasting Union (EBU) of European public-service broadcasters, so it is not predominantly a commercially driven enterprise. However, as we describe below, the work of volunteering is less tied to the actual 
music festival and is more a part of creating "brand values" for cities and places.

Within media studies, there has been an intensive debate on unpaid labour during the last decades. In the early 2000s, the issue was discussed mainly in relation to the production of content by users participating in online platforms: digital media had resulted in competition from amateur producers who created media content for pleasure, self-realization, and peer recognition (Arvidsson 2008). This is still very much an issue, and such "exploitation" of users has deepened since then, not least as a consequence of technological developments. However, the debate on unpaid labour has expanded to include much of the service industry, internships, outsourcing, and political initiatives to force the unemployed to do unpaid work (Precarious Workers Brigade and Carrot Workers Collective 2014). An obvious case of unpaid labour in the media industries is the internship system. It is increasingly difficult to enter media-related industries without having performed a significant period of unpaid work at some point in the form of an internship (Frenette 2013, 2015). This development is spurred, at least in part, by the desirability of creative labour and by a simultaneous over-supply of workers (Hesmondhalgh 2010).

Volunteering as a form of unpaid labour has not been extensively discussed in relation to the media industries in previous literature. Media work generally refers to work done by professionals within the media industries; more specifically, it refers to the work done by "symbol creators", or the creators of cultural texts (Hesmondhalgh 2013). Because the media deals in ideas, information, and culture, the management and organization of media work has been seen as somewhat different than in many other organizations; for example, media work is seen as affording a higher degree of autonomy for workers (Deuze 2007). Volunteers at media events such as the ESC are rarely "symbol creators" of this kind, and are seldom directly involved in the production of the television broadcast as a cultural text. Instead, their work must be seen as aligned with what Mayer (2011) discusses as "below-the-line work": the tasks performed by these volunteers are often simple and routine, and the volunteers themselves have neither high status nor influence in the organization. Nevertheless, their efforts, which are both of a practical character (i.e., carrying, building, moving, guarding, etc.) and of a more symbolic and communicative nature (i.e., talking to guests, setting the mood, creating eventfulness), are intrinsic to the media production (i.e., the ESC) and to the event as such. In general, the form of labour that is performed by volunteers at cultural events such as the ESC is a good example of unpaid media work in which, as argued by Fuchs (2014), the boundaries between play, leisure, and labour have become increasingly fuzzy. To describe this phenomenon, Fuchs (2014) introduced the term "play labour", which refers to the fact that exploitation - in the economic sense of the term - increasingly tends to feel like fun and leisure, and thus becomes a part 
of individuals' free time (122ff).

Free labour entails work that is simultaneously freely given (i.e., unpaid) and enjoyed by those doing it; in addition, it is exploited and constrained. Andrejevic (2009) interprets free labour as a (new) form of capitalist logic whereby the production of community and sociality is "both autonomous of capital and captured by it". In events such as the ESC, the community and sociality are bound up with the notion of an "event" as such - that is, a common shared experience - and, as expressed by several of the participants, with the notion of something "bigger" that the individual work experience is folded into and obtains meaning from. These notions are conceptualized here within the idea of eventfulness. Eventfulness is both the "product" that volunteers produce during the event, and the "experience" that creates meaning for the volunteers and that must be purposefully premeditated, planned, and produced for them by the organizers of the ESC. In sociological theory, an event is "an act or incident" that is clearly contrasted "to the going order of things, its disruption of that order" (Sahlins 1991:45). Events are made to happen and are loaded with the symbolic capacity of transforming or reproducing the structure or the order of things. Eventfulness then, is the experience or feeling of participating in a (significant) event and, as stated by Moore (2011), "specific events is shaped by how their eventfulness and significance comes to be interpreted".

The driving forces behind volunteering have generally been seen as partly altruistic (i.e., wanting to do good for the community at large) and partly egotistic (i.e., wanting to gain work experience, express one's values and beliefs, look for new friends, etc.) (Rehberg 2005, Smith 1981). Motivations can be both individual and social, and can both relate to fundamental human needs (such as belonging and community) and be interpreted as linguistic explanations that people use when asked why they are doing what they are doing (Clary et al. 1998). From such a perspective, motivation is a social construct, and people acquire a repertoire of justifications for their actions that is dependent on cultural and social contexts. In the context discussed here, eventfulness is a key issue; hence, this article will explore how the discursive and rhetorical construction of eventfulness takes place at the "media event" (Dayan \& Katz 1992) of the ESC.

Following the framework laid out above, we will address eventfulness as a sort of currency. Volunteering is indeed a form of unpaid labour; however, an important part of volunteers' compensation is the symbolic forms (ideas, stories, identities) they receive, which are intermingled with and support the economic functions of volunteering. The main part of this article involves unpacking and analysing these dimensions of volunteering. As we will show, volunteering is largely about eventfulness, and an understanding of the role of eventfulness is crucial for a full understanding of the political economy of contemporary volunteering in the media industries. 


\section{Entry points}

This article is based on interviews with the volunteers and the organizers of the volunteers during the 2016 ESC in Stockholm and the 2017 ESC in Kyiv (see Table 1 for an overview).

\begin{tabular}{|l|l|}
\hline Informant 1 & Volunteer, woman, 20s. Kyiv. \\
\hline Informant 2 & Volunteer, woman, 20s. Kyiv. \\
Informant3 & Volunteer, woman, 20s. Kyiv. \\
Informant 4 & Volunteer, woman, 20s. Kyiv. \\
Informant 5 & Volunteer, woman, 20s. Kyiv. \\
Informant 6 & Volunteer, woman, 20s. Kyiv. \\
Informant 7 & Team leader, woman, 20s. Kyiv. \\
Informant 8 & Team leader, woman, 20s. Kyiv. \\
Informant 9 & Volunteer trainer, woman, 50s. Kyiv. \\
Informant 10 & Volunteer organizer, man, 40s. Kyiv. \\
Informant 11 & Volunteer organizer, woman, 40s. Kyiv. \\
Informant 12 & Volunteer organizer, woman, 40s. Stockholm. \\
Informant 13 & Volunteer, woman, 50s. Stockholm. \\
Informant 14 & Volunteer, woman, 20s. Stockholm. \\
Informant 15 & Intern at the communication department at the \\
& Stockholm municipality, man, 20s.
\end{tabular}

Table 1 . Overview of the participants in the study.

The participants were recruited in different ways. In Sweden, we obtained assistance from the volunteer coordinator employed by the Stockholm municipality. In Kyiv, Golovko used personal contacts, professional networks, and social media to contact and recruit volunteers and people working with the volunteer organization in the Ukraine. The interviews in Stockholm were conducted after the event, in June and during the fall of 2016. In Kyiv, we were part of a larger research group that did fieldwork on several aspects of the ESC in Ukraine. We visited the capital during the week of the ESC (May 7-14, 2017) and conducted the interviews at that time. The bulk of the Ukrainian interviews were conducted in English, although Golovko also translated questions into Russian or Ukrainian. During the event in Kyiv, we also had the opportunity to observe the volunteers in action - both in the city centre, where they worked at five ESC locations, and at the broadcasting location outside the city centre. The interviews lasted for 30-90 minutes and were recorded. In addition to the interviews, we used written materials: mainly the volunteer handbooks (from Stockholm and Kyiv, respectively), but also the 
Stockholm city council reports summarizing the results from the 2016 ESC. The material was transcribed and analysed thematically according to five broad questions: (1) What do the volunteers at this media event do? (2) How is volunteering organized? (3) How do the volunteers themselves understand their role? (4) What motivates volunteers at large media events such as the ESC? and (5) How does the organization/leadership work to create and uphold motivation?

\section{Organizing volunteering}

There were significant differences in how volunteering was organized in the two ESC events that we followed. In Sweden, the municipality of Stockholm had a total of 450 volunteers that were engaged in the event. In Ukraine, the municipality of Kyiv had a single volunteering operation with about 500 volunteers. This operation was not, however, directly organized by the city of Kyiv; rather, it was run through an organization called Volonter, which can be described as something between an NGO and a private corporation. In addition to these volunteers, who mainly worked within the city of Kyiv, the television broadcaster organized 900 volunteers who worked at the ESC arena and with the television production.

Using volunteers for a large event such as the ESC requires a professional organization with paid employees who recruit, train, and manage the volunteers before and during the event. In the Swedish case, the entire organization that was needed for the volunteer operation was created in-house within the Stockholm municipality organization. The head of the volunteers was borrowed from the Stockholm Tourist Agency (a public enterprise), and the team leaders and managers were chosen from different municipal companies and administrations, and were temporarily taken from their ordinary jobs for the period of the ESC (two weeks in May). In the Ukrainian case, the situation was different. The 500 volunteers employed by the city of Kyiv were recruited and trained by the British company People First, which describes itself as a "multisector recruiter" on its company webpage (people-first.co.uk, 2017-09-08). Furthermore, the volunteers were not managed through the municipality, but by a semi-private organization (Volonter). In Ukraine, it is not unusual for NGOs - rather than the state or municipal governments - to organize the greater part of the administration and governance of the country. Volonter is one example of an $\mathrm{NGO}$ /private enterprise with close ties to the political sphere; for example, it is headed by the mayor of Kyiv, Vitali Klytjko. 


\section{The politics and economics of volunteers at the ESC}

Volunteering at an event like the ESC is connected to political and economic ambitions regarding "city branding" and "stimulating the volunteer sector" in public administration. It is also connected to economic motives regarding savings to be made in public budgets, and to a surrounding volunteer industry that is responsible for recruiting, hiring, and training volunteers.

As pointed out by Holst-Kjær (2011), cultural events such as the ESC - and the way in which they are used and framed among political and economic elites exemplify the recent debate in cultural policy and experience economy about the "cool city". The premise for these debates is that it is important for a city to have the right "brand value" in order to attract the "right" kind of inhabitants and businesses, and in order for the city to flourish (Ashworth \& Kavaratzis 2016; Kavaratzis 2004). For politicians and policy-makers, it hence becomes increasingly important not only to govern, but also to market, communicate, and brand the city. To host the ESC is seen as (and used as) an opportunity to establish the image of the host city. An important part of this opportunity is that the host city chooses the overall theme and "tagline" for the event, which is used in all communication and marketing, and which is intended to communicate the values that the branding and marketing teams from the host city want to associate with that city. In Stockholm, the tagline for the event was "Come Together"; in Ukraine, it was "Celebrate Diversity". In many ways, these catchphrases seem to be (and are) empty signifiers that anyone is free to fill with meaning and interpretations. However, the general intention behind them and the interpretation of them (among commentators, the public, people working with the event, etc.) relate not only to branding issues but also to political issues - such as the need for unity and friendship in Europe and among Europeans, or the need for respect and tolerance for difference. The volunteers in both Sweden and Ukraine were understood - by their managers and by themselves - to be the representatives and bearers of the content of these slogans. The volunteers described how, during their training, they "discussed in groups what it means to be the ambassador of the country and how to be a great volunteer" (Informant 4) as well as "the history of the tagline - how to understand the meaning of 'celebrate diversity"' (Informant 9). However, the expression of political meaning that is inherent in having volunteers "represent" the tagline - which is politically and economically motivated and defined - is not the only way in which volunteering is related to political and economic power. In the case of the ESC, the event is directly organized (i.e., recruiting, training, employing volunteers) through public authorities that are politically governed. In both Stockholm and Kyiv, the municipal authorities and political actors understood the large scale of the volunteer organization of the ESC to be a way of stimulating and exploring possibilities for engaging volunteers in future public work projects. In the Ukrai- 
nian case, this concept has taken the form of a growing "volunteer movement" that encompasses an increasing number of societal sectors. Our informants explicitly connected this movement to the ongoing political and military crisis in the country. For example, in the words of the Ukrainian organizer of the volunteers:

The situation has changed after the revolution in 2014. These days, a lot of young people become volunteers during the Eurovision to do something useful for the country. The volunteering in Ukraine is developing very fast and rapidly. Especially, it became noticeable after the Euromaidan. (Informant 10)

In the interviews, the volunteers themselves elaborated further:

The volunteer movement in Ukraine is becoming stronger; it has a long history, but now it's starting to be normal to be a volunteer - that you do something... and help people. We also talked about this during training - that you shouldn't stop being a volunteer just because Eurovision ends. Volunteering is something you can, and should be [doing], every day, always. (Informant 2)

This perspective of volunteering does not only relate to the specific Ukrainian political situation; it is also connected to more general tendencies to increasingly use and exploit unpaid or low-paid labour (e.g., interns, the "gig economy", contributors of material to digital networks, etc.). Unlike commercial companies, public bodies receive no direct economic profit from such volunteering. Of course, savings can be made in public budgets as volunteering becomes more widespread and common in different forms of activities. This was also clearly understood and elaborated by the informants, who in the interviews regularly commented on the fact that they were used in order to "save money" on behalf of the organizers and that their services were contributing to the event, "while we of course work for free". (Informants 3, 4, and 5). Traditionally, most volunteer work has been organized in the so-called "third sector", or civil society. In the case of the ESC (and other similar mega-events) the state, the market and corporate world, and the third sector intermingle in complex ways, which introduces - sometimes directly and sometimes indirectly - a corporate profit motive into the area of volunteer work. In the Ukrainian case, the situation is even more complicated, as private corporations often take the form and shape of NGOs, while simultaneously having strong formal links to state power and political interests. To summarize, volunteering at cultural events such as the ESC is strongly connected to various political and economic goals and ambitions. These include savings in public budgets, profits for the 
host city, profits for different companies in the "volunteering industry" that supply and train volunteers, and - most importantly - city branding, to which volunteers can contribute and add to the "brand value" of the host city by increasing the eventfulness of the ESC as a media and cultural event.

\section{Enhancing eventfulness: The work of volunteering at the ESC}

Volunteering at the ESC can entail a range of different things; however, volunteers generally perform routine tasks that must be done but that are too expensive to use waged labour to carry out. One of the participants describes these tasks as follows:

We help people, guide them, answer questions, entertain them; we also move things, carry equipment, and so on. We work all the time; there is always something to do, and no time to just hang around or rest. (Informant 4)

The above description, which was given by one of the volunteers from Kyiv, is a typical one. Most of the volunteers we interviewed worked as cloakroom attendants, gatekeepers to clubs and VIP areas, drivers, and crew in information centres. During the 2017 ESC in Kyiv, volunteers also worked directly with the television production, including script-writing and stage work.

Labour law and the collective agreements between unions and employers affect what volunteers are permitted to do. In Sweden, it is fairly difficult to have proper jobs be performed by volunteers - at least, the tasks volunteers perform cannot be described as proper jobs. One of our informants, a PR assistant for the municipality of Stockholm, told us how he was scolded by his manager for using the word "work" in a press release about the volunteers of the 2016 ESC, since "it is of utmost importance that we do not openly describe what they do as a form of work" (Informant 15). In the Volunteer's Handbook for the 2016 ESC in Stockholm, the activity of volunteering is described as "being an ambassador" (i.e., of the event, of the city of Stockholm, and of Sweden), "offering good service", and "spreading magic". It is notable that none of the descriptions in the Handbook mention words such as work or labour. The organizers of the 2017 ESC in Kyiv were not as strict as those in Stockholm; the manager in charge of the volunteering organization in Kyiv spoke more openly in terms of the volunteers working and performing a proper job. For example, she commented on the long shifts of the volunteers as follows:

To be a volunteer is hard work, they work for long periods of time. It 
is impossible to organize them in shifts, so at least some of them must work for 12 hours straight. Therefore, they need to be well-motivated. (Informant 11)

However, in both cases, there was a significant tendency on the part of the organizers and managers not to describe volunteering as an essential part of the event, but rather to describe it as adding something extra, contributing to the festive feeling, and setting the mood of the event - as if the volunteers were mainly a kind of decoration used to create an eventful atmosphere in the host city. For example, the Swedish head of volunteering described the purpose of volunteering as "adding something extra, putting a filter of festivity over the whole event" (Informant 12).

Beyond routine tasks, one key role that volunteers played in these events was that of visibility. Their contribution to the "positive buzz" and the feel of festivity that the organizers sought to produce came first and foremost by their presence: the physical presence of their bodies on the street. The Eurovision event stretches out over a period of two weeks. During the first week, artists and their crews, fans, and tourists start arriving in the host city. The second week entails the broadcasting events, the two semi-finals, and the concluding Eurovision final on Saturday evening. During the entirety of this period, in both Stockholm and Kyiv, volunteers were stationed at several locations in the downtown area where participants and guests of the events were supposed to meet, mingle, and experience various cultural programmes such as concerts. These so-called "Eurovision zones", located in city squares, were places where the event took on a material form and shape beyond the televisual experience of the broadcasting of Eurovision. The volunteers occupied the scene at these zones, marking with their very presence the fact that something was going on. According to Scannell (2002), events are human-made moments that stand out from the ordinary flow of everyday experience; events have a "prospective meaningful character" (ibid.). Events are prepared, eagerly awaited, and invested with expectations; most importantly, they are designed to give us a positively anticipated experience (i.e., we look forward to the experience of being part of the event). The Eurovision zones and the presence of volunteers are designed to create expectation and anticipation (i.e., that the Eurovision event will take place); however, they also mark an "out-of-the-ordinary" moment: something is happening. Thus, the volunteers are there to be seen. This perspective came up in the interviews, as follows:

I'm in my uniform. I have my pass. And everyone sees that I am a part of this. And everyone pays attention and looks. And it's cool. I like it. (Informant 3) 
In addition to creating the feeling that something out of the ordinary is occurring, volunteering during cultural events such as the ESC creates a sense of urgency: something is happening right now. Borrowing a term from television studies, we can say that in this sense, volunteers contribute to the "liveness" of the event (Auslander 2008) - that is, they help create an atmosphere in which visitors feel that they are participating in something that is being played out at this moment.

This combination of presence and "liveness" creates the eventfulness that is sought by the organizers and that is a key feature of volunteering in cultural events, in addition to practical and routine volunteering tasks. Another important element in creating festivity and a sense of eventfulness is the message of abundance that volunteers send through their presence at the key sites of the event. As stated by the volunteer organizer in Stockholm:

Honestly, I can say that...we actually had volunteers to offer a kind of extra and spectacular hosting. That is what it is about, you know. The event itself, of course we could host this event entirely without volunteers. But if we have them, it gives something more, something extra. (Informant 12)

Volunteers are present to send a message of care. The services provided by volunteers are generally not necessary in the strictest sense of the term. There are maps for those who need to find their way through the city, and there are police officers for those who feel unsafe. However, the deployment of volunteers at the key sites of the event is as much about symbolic labour as it is about actual, concrete work: it shows that effort is being made to take care of guests and visitors.

\section{Experiencing eventfulness: Motivations for volunteering at the ESC}

In this final part of the analysis, we will move on to show that eventfulness is not only an effect of the volunteers' work, or a mood that they must share in order to express it to guests and visitors; it is also a central symbolic currency that is used to "buy" the labour power of volunteer workers. As discussed above, in theories of free labour, such labour is generally described as simultaneously freely given and enjoyed by those doing it, while also being exploited and constrained. The "enjoyment" of such work has often been seen as unproblematic and natural, and not as something that is actively produced and maintained by those organizing the labour. However, the example of ESC volunteering shows that this "enjoyment" of free labour is a crucial form of renumeration that is acknowledged and actively produced by the "buyers" of labour (i.e., the organizers of the ESC). 
Among the participants in this study, no one expressed hope or anticipation that volunteering would benefit their future career in the media and cultural industries (or elsewhere). The people we interviewed were not particularly interested in - or fans of - the ESC as such, even though we had expected this to be an important reason for volunteering at the ESC. To some extent, other altruistic motivations were expressed by the participants, such as "helping our nation" and "doing something for the community" (Informants 1, 3, 5, 8, and 13). Most importantly, however, the people we interviewed for this article expressed the motivations of wanting to be a part of the event and wanting to experience the extraordinariness and eventfulness of the event as such. The ESC can be understood as a "media event", as defined by Dayan and Katz (1992) in their study on media events (c.f. Ericson et al. 2002). The ESC is a large-scale symbolic event with possible social consequences, and a central dimension of the ESC is the eventfulness that it entails and that must also be produced by the organizers of the event. This perspective was expressed in most of the interviews that we conducted, both in Sweden and in Ukraine. For example:

The emotions that I get from the volunteering are what I get back. And being part of something BIG makes me the happiest person ever. (Informant 4)

So, it's like to be a part of something that is all over the world. To be part of something bigger. (Informant 1)

The emotions it evokes, the grand look of the arena and this happy and festive mood - that is what makes me engaged in this event. (Informant 6)

I like being, I like that feeling that I am a small part of something big. That I am involved in something that is so huge, so big, that the whole world knows about it. (Informant 5)

This view relates to the point made by Nick Couldry (2000) about the mystique and allure of the actual sites of mediated spectacles: that those spaces, mundane as they might be, draw people in as "pilgrims" seeking to visit, witness, and partake in the "place of media power". For Couldry, this attests to the ideological notion of the media as being "the centre of society", and pilgrimages to the sites of media spectacle reinforce this notion. In a similar vein, the volunteers at the ESC seek participation and belonging to "something bigger" at the very mundane and everyday sites where the televised spectacle of the ESC "hits the street". At the 
same time as the volunteers talk about their hopes to belong and feel "part of something" in the interviews, the actual work and routine tasks that they perform, as described above, seem to distance them from the event and from the eventfulness of the ESC. Volunteers sometimes work in areas that are remote from the "action" (i.e., from the actual broadcasts or festivities). Even when they do work at locations that are central to the event, the tasks that volunteers perform draw them out of the general eventfulness. This is acknowledged by the managers of the volunteers; in fact, the managers work to include the volunteers in the event and to maintain the spirit of the event among them. This is done, for example, by providing continual information about what is going on in the main arena, through social media updates, and through continual pep talks to maintain volunteers' focus on what the event is about.

One of the Kyiv volunteers described how the management worked hard to "get us to feel like a part of the event", through:

...written programmes and showrunners for each location, we have team meetings every day with information about what is going on. We also get uniforms such as T-shirts, jackets, baseball caps, and special badges with public transportation cards; that separates us from all other people and it makes us feel "special", or as a team, as real participants. We also have our Facebook groups, and there is lots of stuff to do and participate in. (Informant 3)

The organizers and managers of the volunteering at both the events underlined the importance of "creating an experience" for the volunteers. For example, the head of volunteering at the 2016 ESC in Stockholm stated:

It is of great importance that this becomes a positive experience for the volunteers themselves. We really wanted to create an experience for the volunteers. We only had two weeks to do it, but we really wanted to boost them as much as we possibly could so that they would leave the event feeling like, "Wow!". (Informant 12)

To enhance (or create) a feeling of eventfulness and belonging among the volunteers, the organizers used a range of tools, some of which are commonplace in team-building activities in working life in general, and others that are unique in volunteering.

The focus on belonging and eventfulness began early, during volunteer training before the events in May. Several days of training in preparation occurred in both Stockholm and Kyiv (Fig. 1). As mentioned above, language, security, and 


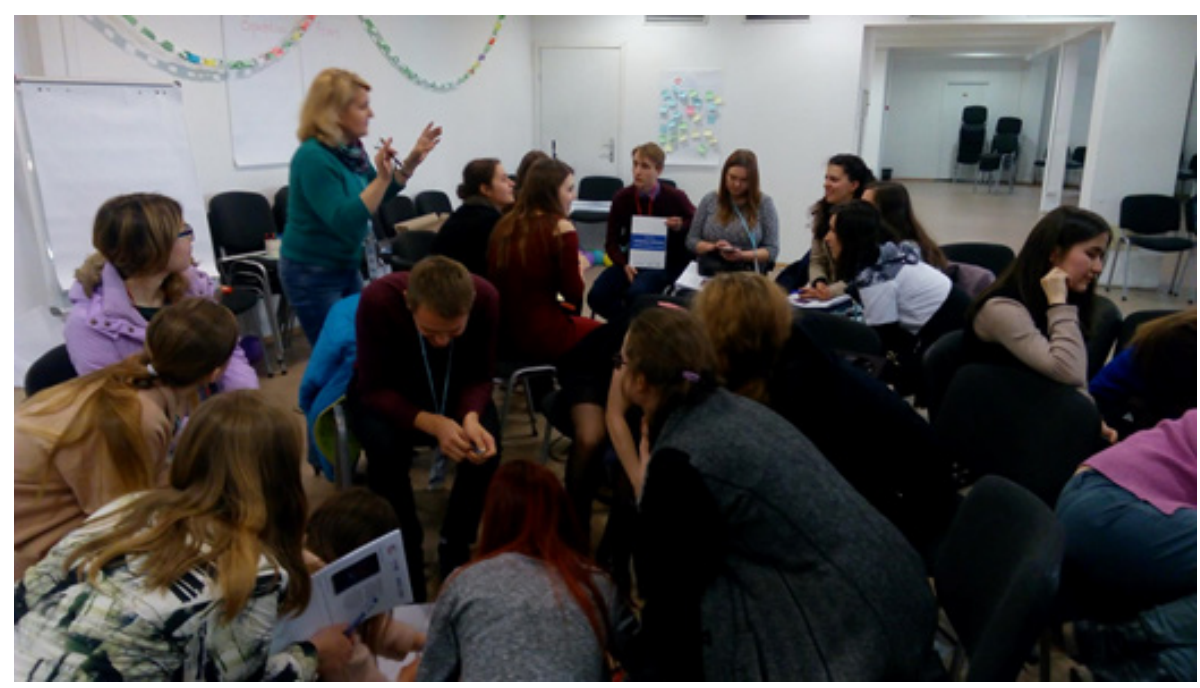

Fig. 1. Volunteers engaged in a team-building task during the training.

basic Eurovision knowledge were part of the training; another part of the training was to prepare the participants to play the role of volunteers in the street and to act as visible elements "representing" the event. Hence, as formulated by the head of volunteering in Stockholm, an integral part of the training was "to set the mood" among the volunteers. In Kyiv, one of the staff members responsible for the training described it as follows:

One of the most important aims of the training is to create a feeling that they (volunteers) are a part of the team. In other words, it is a team-building activity in many ways...to keep up volunteers' enthusiasm and excitement. (Informant 9)

Parties and ceremonies for the volunteers were also important in enhancing the feeling of eventfulness and of being a part of the event. Such events were hosted in Kyiv and in Stockholm both before and after the ESC. For example, on April 25, 2017 , the 900 volunteers gathered in the main square of Kyiv for an opening ceremony. To make it even more official, the mayor of Kyiv, Vitali Klytjko, delivered a welcoming and inspiring speech. He thanked the volunteers for their devotion and for their desire to make Kyiv a city that foreign guests would remember forever. $\mathrm{He}$ also highlighted everyone's responsibility for the guests' impressions during their time in Kyiv. "But I am sure, they will be only positive ones", he concluded. Following Klytjko's speech, the event manager of Eurovision, Kyrylo Voronin, and a former ESC winner, the artist Ruslana Lyzhychko, wished the volunteers the best of luck in their job; then hundreds of blue balloons flew into the sky (Fig. 2). 


\section{Culture Unbound}

Journal of Current Cultural Research

The training, ceremonies, and parties were important before and after the event took place. In the weeks of the ESC itself, however, there was no time for such things. During the event, the most important tool that was used to maintain the feeling of eventfulness and community was social media. As mentioned above, volunteers' tasks during events such as the ESC are often tedious, and may be removed from the centre of the event. Therefore, social media can facilitate the feeling of being a part of the event as it unfolds (see Kaun \& Uldam 2018 for an analysis of the interrelation between social media and volunteering).

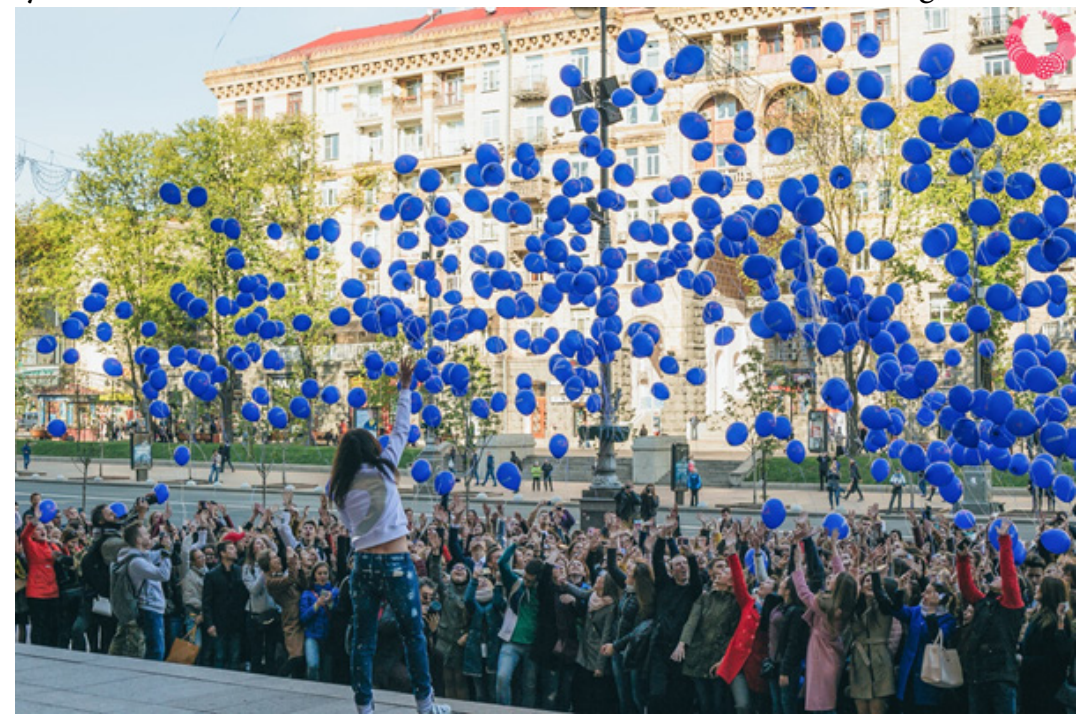

Fig. 2. Blue balloons fly into the sky at the opening ceremony for the ESC volunteers in Kyiv, as the prior winner of ESC, Ruslana Lyzhychko, waves to the crowd of volunteers

A closed Facebook group, initiated by the National Television Channel, was central in this respect. The organizers tried to gather all the volunteers into one group to create a virtual space where they could make friends and share their experience. There was even a special media team that took photos of volunteers at work and posted them on the Facebook page in order to boost the immediacy and "liveness" of the work itself, and to help the volunteers experience a sense of belonging and immersion in the event. The manager of the volunteers at the National Public Broadcasting Company of Ukraine (UA:PBC) in Kyiv said:

We also have the volunteer media team. Two volunteers are specially assigned to take photos and videos of the volunteers during their work. It is not allowed for the volunteers to shoot photos and videos. They should work; they should not take autographs and take selfies with celebrities. It is not allowed to post photos of the event in social media. We 
have a Facebook page and they (media volunteers) are moderating this page and posting the photos. (Informant 11)

Considering what the event managers say and do to organize volunteering for a cultural and media event such as the ESC, it is evident that the experience of eventfulness is a key element, not only for the visitors to the event, but also for the volunteer staff. This experience can be interpreted as a key resource that the organizers must produce, enhance, and manage in order to motivate the volunteers and maintain their interest in undertaking the free labour that is necessary for the event to take place.

\section{Conclusion}

This article discusses how volunteering is an important form of media work that takes place in relation to large media events such as the ESC, and thereby presents a perspective of volunteering that has been somewhat overlooked in the previous literature. We argue that such volunteering activities must be seen as intrinsic parts of the event, and that the work done by volunteers is a form of labour. We view volunteering at major media events as labour in two ways: first, it is part of the production of economic surplus for the organizers of these major events; and second, it plays an important role in the production of "brand value" for the cities, municipalities, and countries that are attempting to use the event for place-branding purposes.

Since volunteering must be seen as a form of unpaid or free labour, the question of motivations and social values becomes important. This article shows that eventfulness is an essential part of what volunteer labour brings to an event such as the ESC. It is also a key element in the production of economic value: eventfulness is a currency that expresses the value of the event itself and is a key feature of place branding. Furthermore, eventfulness - along with the feeling of being a part of an event, of something bigger, as it unfolds in time - is a key feature of the motivation of the volunteers who contribute with unpaid labour. As such, eventfulness can also be understood as a form of currency or symbolic capital that forms the main remuneration or "wage" earned by volunteers at an event such as the ESC. However, the currency of eventfulness is not necessarily spontaneously produced as the event unfolds; there is a risk that the experience of volunteering will fall into uneventfulness, as volunteering tasks are often both routine and remote from the actual event. Therefore, the organizers in both Kyiv and Stockholm had to premeditate, plan, and produce eventfulness for the volunteers. At huge media events such as the ESC, the organizers work to produce eventfulness not only as a value for the consumers of the event (i.e., the audience in front of the television and 
the people gathering onsite), but also as an internal experience within the organization and for the volunteers. If anything, this finding points to the fact that no labour is ever entirely unpaid, and that while volunteering is indeed a form of free labour, an important part of the compensation that volunteers receive is a feeling of identity and belonging that comes with the experience of eventfulness.

These findings may contribute to the field of research on voluntary work, as they demonstrate - in line with the work of Salomon and Sokolowski (2016), for example - the complexity and messiness of relations between volunteering and the state and market. The third sector of civil society is often intertwined with commercial and political powers, which is especially true in the Ukrainian case; voluntary actions might hence be circumscribed within the logics of capital and state, with a range of possible - but somewhat overlooked - consequences to be elaborated in further research. Furthermore, commercial interests and for-profit companies can - and have been reported to - seek ways to exploit the idea of volunteering; for example, they may recruit "volunteers" instead of interns as increased labour regulation and policy make it increasingly difficult to use unpaid interns as a resource.

The findings presented here may also contribute to research on media work and work in the cultural industries, as they highlight how so-called free labour, or "playbour", includes specific forms of "wage" or renumeration that must be actively premeditated and produced by employers or by those who wish to use unpaid workers. How this happens, what kind of work goes into this, and with what consequences have only been touched upon in this article, and more work is necessary. The results from this study also urge us to widen the empirical scope in studies of media work to include groups such as interns and volunteers, in analyses of how media and cultural events are produced and come to be.

Fredrik Stiernstedt is Associate Professor in Media Studies at Södertörn University, Sweden. His research concerns work and labour in the media and cultural industries, as well as issues of social class and media. E-mail: fredrik.stiernstedt@ $\underline{\text { sh.se }}$

Irina Golovka holds a Master of Arts from Södertörn University and the research conducted for this article was part of her master thesis. 


\section{Culture Unbound}

Journal of Current Cultural Research

\section{References}

Andrejevic, Mark (2009): "Exploiting YouTube: Contradictions of User-Generated Labor," Pelle Snickars \& Patrick Vonderau (eds): The YouTube Reader, Stockholm: National Library of Sweden, 406-424.

Arvidsson, Adam (2008): "The Ethical Economy of Customer Coproduction," Journal of Macromarketing, 28:4, 326-338.

Ashworth, Gregory, and Mihalis Kavaratzis (2016): "Cities of Culture and Culture in Cities: The Emerging Uses of Culture in City Branding," Tigras Haas \& Krister Olsson (eds): Emergent Urbanism: Urban Planning \& Design in Times of Structural and Systemic Change, London \& New York: Routledge, 73-80.

Auslander, Philip (2008): Liveness: Performance in a Mediatized Culture, London \& New York: Routledge.

Banks, John \& Mark Deuze (2009): “Co-Creative Labour,” International Journal of Cultural Studies, 12:5, 419-431.

Banks, John \& Sal Humphreys (2008): “The Labour of User Co-Creators: Emergent Social Network Markets?” Convergence, 14:4, 401-418.

Clary, E. Gil, Mark Snyder, Robert D. Ridge, John Copeland, Arthur A. Stukas, Julie Haugen \& Peter Miene (1998): "Understanding and Assessing the Motivations of Volunteers: A Functional Approach," Journal of Personality and Social Psychology, 74:6, 1516.

Couldry, Nick (2000): The Place of Media Power: Pilgrims and Witnesses of the Media Age, London: Routledge.

Dayan, D. \& E. Katz (1992): Media Events: The Live Broadcasting of History, Cambridge, Mass.: Harvard University Press.

Deuze, Mark (2007): Media Work, Cambridge: Polity.

Duffy, Brooke Erin (2017): (Not) Getting Paid to Do What You Love: Gender, Social Media, and Aspirational Work, Yale: Yale University Press.

Dunnett, Chris (2015): “How Volunteers Created A 'Second State' Inside Ukraine. Massive and Unprecedented Volunteer Movement Fills the Void Where the State Fails," Hromadske International, Jan 31, 2015.

Ericson, Staffan (red.) (2002): Hello Europe! Tallinn calling!: Eurovision Song Contest 2002 som mediehändelse, Huddinge: Medie- och kommunikationsvetenskap, Södertörns högskola.

Frenette, Alexandre (2013): "Making the Intern Economy: Role and Career Challenges of the Music Industry Intern," Work and Occupations, 40:4, 364-397.

Frenette, Alexandre (2015): "From Apprenticeship to Internship: The Social and Legal Antecedents of the Intern Economy," TripleC: Communication, Capitalism \& Critique. Open Access Journal for a Global Sustainable Information Society, 13:2, 351-360.

Fuchs, Christian (2014): Digital Labour and Karl Marx, London \& New York: Routledge.

Gill, Rosalind, and Andy Pratt (2008): "In the Social Factory? Immaterial Labour, Precariousness and Cultural Work," Theory, Culture \& Society, 25:7-8, 1-30.

Hesmondhalgh, David (2010): "User-Generated Content, Free Labour and the Cultural Industries," Ephemera, 10:3-4, 267-284.

Hesmondhalgh, David (2013): The Cultural Industries, London: SAGE.

Holst-Kjær, Sarah (2011) "Meaningful-Experience Creation and Event Management: A Post-Event Analysis of Copenhagen Carnival 2009," Culture Unbound: Journal of Current Cultural Research, 3:2, 243-267.

Kaun, Anne \& Julie Uldam (2018): "Volunteering is like any other business': Civic participation and social media," New Media \& Society, 20:6, 2186-2207.

Kavaratzis, Michalis (2004): "From City Marketing to City Branding: Towards a Theoretical Framework for Developing City Brands," Place Branding, 1:1, 58-73. Kuehn, Kathleen, and Thomas F. Corrigan (2013): "Hope Labor: The Role of Employ- 
ment Prospects in Online Social Production," The Political Economy of Communication, 1:1, 9-25.

Lindgren, Simon (2014): "Crowdsourcing Knowledge Interdiscursive Flows from Wikipedia into Scholarly Research," Culture Unbound: Journal of Current Cultural Research, 6:3, 609-627.

Lundström, Tommy \& Lars Svedberg (2003): "The Voluntary Sector in a Social Democratic Welfare State-The Case of Sweden," Journal of Social Policy, 32:2, s. 217-238.

Mayer, Vicki (2011): Below the Line: Producers and Production Studies in the New Television Economy, Durham, N.C.: Duke University Press.

Moore, Adam (2011): "The Eventfulness of Social Reproduction," Sociological Theory, 29:4, 294-314.

Osman, Kim (2014): "The Free Encyclopaedia That Anyone Can Edit: The Shifting Values of Wikipedia Editors," Culture Unbound: Journal of Current Cultural Research, 6, 593-607.

People First (2017): people-first.co.uk (accessed 17/09/08).

Precarious Workers Brigade and Carrot Workers Collective (2014): "Free Labour Syndrome. Volunteer Work and Unpaid Overtime in the Creative and Cultural Sector," JOY FOREVER, 211.

Rehberg, Walter (2005): "Altruistic Individualists: Motivations for International Volunteering among Young Adults in Switzerland," Voluntas: International Journal of Voluntary and Nonprofit Organizations 16:2, 109-122.

Rochester, Colin, A. Ellis Paine, Steven Howlett, Meta Zimmeck \& Angela Ellis Paine (2016): Volunteering and Society in the 21st Century, Berlin: Springer.

Sahlins, Marchall (1991): "The Return of the Event, Again: With Reflections on the Beginnings of the Great Fijian War of 1843 to 1855 Between the Kingdoms of Bau and Rewa," Aletta Biersack (ed): Clio in Oceania: Toward a Historical Anthropology, Washington, DC: Smithsonian Institution Press, 37-100.

Salamon, L. M., \& S. W. Sokolowski (2016): "Beyond Nonprofits: Re-Conceptualizing the Third Sector," VOLUNTAS: International Journal of Voluntary and Nonprofit Organizations, 27:4, 1515-1545.

Scannell, Paddy (2002): "Big Brother as a Television Event," Television \& New Media, 3:3, 271-282.

Smith, David Horton (1981): “Altruism, Volunteers, and Volunteerism, " Journal of Voluntary Action Research, 10:1, 21-36.

Weisbrod, Burton A. (1997): "The Future of the Nonprofit Sector: Its Entwining with Private Enterprise and Government," Journal of Policy Analysis and Management, 541-555. 